\title{
PHONM PENH: CHANGING URBAN FABRIC WITH DEMOGRAPHY - PAST AND FUTURE
}

\author{
Ankitha Veerepalli ${ }^{1}$ \\ ${ }^{1} 4^{\text {th }}$ year student, GITAM School of architecture, GITAM University, Andhra Pradesh, India
}

\begin{abstract}
The fabric of a city flows and weaves itself from the people. Essentially, people make the city and so, their culture, traditions and practices create the spaces in a city/town. The rich relation between man and his cities can be seen in a number of modern day examples, such as Paris, Barcelona, Bangkok and many more. These cities show the myriad beauty in the mix of architecture in the urban fabric and how the natural development, with proper design can give rise to complex, yet organized developments. Phonm Penh, as a riverfront city and the capital city of Cambodia, offers fascinating architecture, vistas of mixed architectural styles and great scope for future architectural development. This paper is an attempt to understand and study the changing urban fabric of a city that has been the glorious historical epicenter of the Khmer kingdom, an ally, victim and refuge during the Vietnam War, a colony of the French and a genocide killing field. This paper is an effort to study factors affecting its urban fabric in the past and present and future scenarios and how this can be used in other mixed socio-cultural settings with a rich and diverse history.
\end{abstract}

Key Words: Urban fabric, architecture, History, development, socio-economy, future

\section{INTRODUCTION}

The city of Phonm Penh has been the focal point of development in Cambodia for decades and even centuries. It is the epicenter of Cambodia and is popularly known as the 'Pearl' of South-east Asia. Its glory days started in the fifteen century with the shifting of the Khmer kingdom from Angkor to Phnom Penh.However, the history of this city started long before it was an established capital of the Khmer kingdom. [1]

The timeline of this city is extreme in terms in all aspects and this lead of a varying amalgamation of architectural characteristics.

Today it is a fast evolving and developing city socially, culturally and economically, in diversity, quantity and quality. Phonm Penh has gone through tremendous changes that shaped the city into how it is today.

While it has some of the best examples of French colonial architecture, it also showcases new Khmer architecture, modern buildings and boasts of a fast developing dense and diverse urban scape. The shaping of urban fabric in this city is unique and there are endless and adventurous possibilities for the urban design and architecture in Phnom Penh.

\subsection{Architectural Timeline And Influences}

The name Phnom Penh is said to originate from a rich widow called Lady Penh. She found statues in a Koki tree in which were statues of Buddha and Vishnu. The hill on which the temple (Wat Phnom) that housed these statues came to be known as Penh's hill, which translated, became the present name of the city. Earlier it was known as Krong Chaktomok, meaning "City of four faces".

The history of Cambodia dates back to $4200 \mathrm{BC}$. There is evidence of stable societies speaking a proper language resembling Khmer has been found from 1st century AD. [2]

The major eras during which architecture bloomed in Phnom Penh are:

1. Khmer Kingdom - 9th -13th Century

2. French colonial Era- 1863-1953

3. Khmer Era under Norodom Sihanouk 1953-1960

4. Khmer rouge Era

5. Independent Cambodia

These eras majorly shaped Phnom Penh's urban fabric and play an important role in its character. The influence of other important factors also adds to its diversity. The urban mass and space scenario changed drastically with the progression of the above eras. [3]

\section{TRANSFORMATION OF URBAN FABRIC}

The Urban fabric transformed over a long period of time through the following Eras and periods.

\subsection{Khmer Era}

The Khmer era blossomed in Khmer architecture, mainly religious buildings and buildings for the royal family. The buildings were all built in a monumental scale, major examples being The Royal Palace and the Silver Pagoda(Fig1C) in Phnom Penh. 

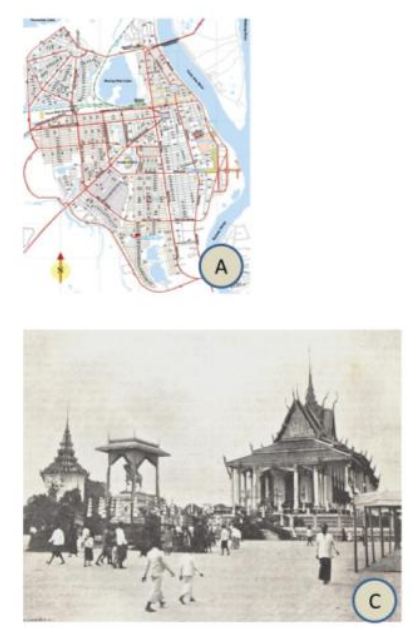

Figure 1: Map of Phnom Penh and changing architecture over the years. [4][5][6][7]

They used intricate carvings in wood, long sloped roofs and spiral ornamentations on top, which came to be typical features of Khmer architecture. It is generally religious architecture where only religious buildings were constructed out of stone and all other typologies were built out of materials like wood and clay.

The space was clearly divided into public and private spaces and these areas were differently grouped. This was because the scale of the residences and the Royal and religious buildings is vastly different.

The public buildings like the Silver pagoda, the Royal palace were monumental in scale and hence served as centers for congregation and public activity. During this time, Phnom Penh was still majorly rural and did not have any major urban identity. Its monuments served as the major landmarks and it had a long way to go to be called an urban area. [8]
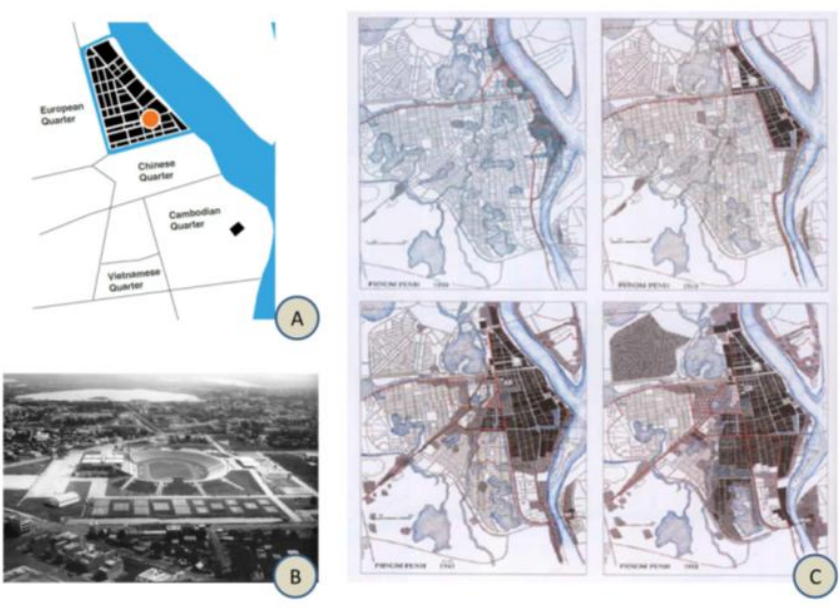

Fig -2: Name of the figure [4][9][4]

The Khmer kingdom gradually declined with a series of invasions by the Ayutthaya and Thai kingdoms and later the Cambodian civil war and the Vietnamese wars.

The Khmer empire then took the assistance of the French in order to sustain themselves, thus ushering the Cambodian French colonial Era.

\subsection{French Colonial Era}

The French are responsible for bringing in the first phase of development to colonial Cambodia.

Phnom Penh was, in this period, divided into several quarters like the French or European quarter, the Chinese quarter and the Vietnamese quarter. Each quarter was planned in a grid system according to the shape in an easy to navigate manner. (Fig 1A) This basic layout was further developed later, during the early independence years of Cambodia. The town developed slowly along the riverside, mainly concentrated in the French quarter. [10]

The development covered the French quarter and slowly spread over parts of the Chinese, Vietnamese and Cambodian quarters by the end of the French rule in Phnom Penh. Around this time the major mix of architecture was between the contemporary French and the Khmer styles, with minor influences of Chinese and Vietnamese styles.

Phnom Penh rapidly developed into an urban center and the urban fabric was an interesting mix of these styles of building and both vernacular and modern materials.

The French buildings, however, always carried a sense of Khmer architecture elegantly fused into their buildings subtly but vividly. The best example for this is the National Museum, Phnom Penh. The French also commissioned modern buildings using Khmer typology as can be seen in the Central market of Phnom Penh, constructed by 1935.

The FCC, Sothearos Boulevard, The general post office(Fig 1B) are the best examples of buildings built in the colonial Era that are being operated even today.

Hotel Le Royal is also a fine example of Cambodian colonial architecture and has been operating as a popular hotel since 1929. [11]

The French took Inspiration from traditional Khmer architecture. The French influence can be clearly seen in the National Museum, which has the typical characteristics of vernacular Khmer architecture and is a classic example of this fusion of architectural styles. This period is one of the most architecturally influencing periods in Cambodia, but its presence is slowly fading away in today's world.

The French did not develop Cambodia as rapidly as they developed their other vassals of Vietnam. However, this period saw the transformation of Phnom Penh from a rural development into an urban area. (Fig 2C)

\subsection{New Khmer architecture}

After Cambodia gained independence from the French in 1953, the second glorious age of Cambodia began, with the advent of New Khmer Architecture. There was fast urban development until the late 1960's. It is a blend of the architecture of Angkor and the simple vernacular building style of Cambodia, along with French modernism.

This style of Cambodian architecture blossomed under the rule of Norodom and resulted in the creation of varied 
buildings in new independent Cambodia. These buildings varied in both style and function, but integrated as being built under the same basic principles. Architect Van Molyvann is the man behind many of these creations and he has brought about a new dimension to the urban fabric of Cambodia. He was the chief royal architect and designed over a hundred structures between 1954 - early 1970's.

His education in France influenced his structures greatly and the influence of Le Corbusier can be subtly seen in his designs. The buildings were built using mainly concrete with vernacular design. They were lifted off the ground and oriented north to avoid flooding and keep the buildings cool respectively. The use of concrete and dynamic structure holds them as a new way of building in Cambodia. A number of these buildings have survived time and can be seen in Cambodia today. The sport's stadium which has a capacity of 60,000 people, the library, apartment buildings for the public ,Chaktomouk Hall(Fig. 3A), Institute for foreign languages, the national theatre are the most important buildings in this Era.

The cumulative nature of this urban fabric is charming and engaging. It plays to the human scale and brings a distinct quality to the city's urban scape and its skyline.

At the same time, the user is regaled with the constant change of shape, architectural style and the age of the buildings. A number of these structures were destroyed during the regime of the Khmer rouge when the complete urban population of Phnom Penh was evacuated and forced to work in agricultural fields.

Today, many of Molyvann's buildings are not in shape and many were destroyed to build new modern day structures with glass and steel. There is no awareness of this dimension of Phnom Penh and no efforts are being made to conserve it. This architecture, clearly ahead of its times is not regarded and given its due in modern day Phnom Penh. Although it makes its presence felt in the urban scape of Phnom Penh, the present cityscape of Phnom Penh is dominated by large modern skyscrapers and concrete buildings that leave a lot to be desired.[12] [13]

\subsection{Khmer Rouge}

During this period, there was a general neglect of the urban scape as the entire urban population was moved out of the city by the then Khmer regime. Several buildings were destroyed and almost the entire city was abandoned.

There was no change in the urban setting in Phnom Penh in this time period apart from the destruction of existing structures. The few buildings and areas that were used in this period carry with them a bloody history of the genocide and the dark period of Cambodia which took the lives of more than 1.7 million people.

The Khmer Rouge regime was a development loathing regime and it turned a developing Phnom Penh into a backward city that has taken years on get back on the track to modern development. All the urban development that was taking place in the city before this regime was left to decay.
Their acts of violence, even today, serve as a reminder of the gory acts of the Rouge regime and the great struggle of the people of Phnom Penh. This forms an important part of modern day Phnom Penh. The killing fields (Fig. 3C), the genocide museum are major examples of remains and evidence of this era. [14]
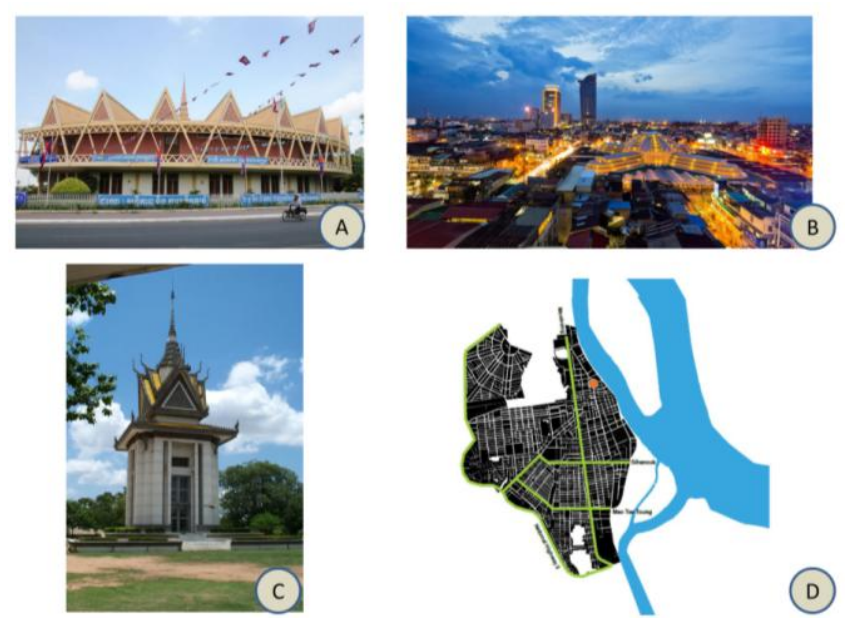

Figure 3: Diversity and development in Phnom Penh [15][16][17]

\section{MODERN DAY PHNOM PENH}

After the urban decay caused by the Khmer Rouge regime, Phnom Penh took a long time to recover from the chaos of the regime and to establish a proper government.

After the stabilization of Cambodia, Phnom Penh was on the verge of a development boom.

With the advent of international and multi-national companies, there was heavy urban development in Phnom Penh. The skyline is dominated by modern high rise buildings and the urban scape is more complex.

There was also demolition of several old structures from the French period and the Khmer independence Era. These and other areas were given for development by the government to real estate companies.

Today, the urban fabric of Phnom Penh is dominated by modern structures and skyscrapers.

The urban scape today(Fig 3B) is an eclectic mix of traditional Khmer buildings, monuments, plain residential blocks, French colonial buildings, buildings from the Norodom era and ruined buildings from bygone eras.

There is a rich mix of vibrant colours and materials. A certain old world charm can be seen in pockets of the urban scape where the colonial buildings are present.

The new Khmer architecture buildings, with their distinct shapes and layouts that are unique to only Phnom Penh give another dimension to the built forms.

The ruins of the city are complimented by the rapidly growing skyscrapers and modern buildings of the city.

The delicate texture of the old world buildings in the urban scape is contrasted by the modern, hard, strong latest built forms. 
The city has grown, both in diversity and density over the years.

\section{CONCLUSIONS}

The present government of Phnom Penh has given permissions for urban development generously, leading to haphazard development and a lot of urban issues. Many heritage structures which add another layer to the urban fabric are neglected and the current development has no threads of connection to the earlier architecture and has vivid contrasting textures in the urban fabric.

Modern Phnom Penh, consisting of such a different and unique urban scape is capable of producing a much better urban character.

In many areas of Phnom Penh, there is no common thread of coherence that can be seen in the building style, if the scale is not considered. A better understanding of the city's rich cultural and architectural heritage is needed in order to build more relevant structures that meld into the urban scape and unify the fabric of the city.

Urban renewal in terms of revitalizing old structures and propagating architecture that is complimentary to Phnom Penh will help create a much better urban scape. Dealing with urban issues such as urban decay, rapid development, services and redefining development laws and building laws of the city will help in a smooth transition of the urban morphology of Phnom Penh into a better version of the existing one.

The identity of a city lies in its urban fabric just as much as it lies in its culture and people. Any development that is carried out keeping this in mind will contribute towards the betterment of the urban character of Phnom Penh.

\section{ACKNOWLEDGEMENT}

I would like to thank Dr. K. Mohan and Prof. Ravindra Patnayaka for guiding me. I would also like to thank Ms. Shelby Doyle for sharing her resources with me. It was very helpful.

\section{REFERENCES}

[1]. History of Cambodia by David Chandler (Westview press)

[2]. National Museum of Cambodia (Cambodiamuseum.info)

[3]. BBC News (http://www.bbc.com/news/world-asiapacific-13006828)

[4]. Shelby Doyle Print Resources https://cityofwater.wordpress.com/print-resources/

[5]. "Central.Post.Office.Poste.Phnom.Penh.1.Cambodge" by Arnaud-Victor Monteux - Own work. Licensed under CC BY-SA $\quad 3.0 \quad$ via $\quad$ Commons https://commons.wikimedia.org/wiki/File:Central.Post.Offic e.Poste.Phnom.Penh.1.Cambodge.jpg\#/media/File:Central.P ost.Office.Poste.Phnom.Penh.1.Cambodge.jpg

[6]. "Pagoda-Norodom-1904 Cambodia" by Priester der Gesellschaft Jesu - Die Katholische Mission - Zeitschrift. Licensed under CC BY 3.0 via Commons -
https://commons.wikimedia.org/wiki/File:Pagoda-Norodom1904_Cambodia.jpg\#/media/File:Pagoda-Norodom-

1904_Cambodia.jpg

[7]. "Silver Pagoda, Phnom Penh" by Original uploader was User: Adam Carr at en.wikipedia - Originally from en.wikipedia; description page is/was here.. Licensed under Public Domain via Commons https://commons.wikimedia.org/wiki/File:Silver_Pagoda,_P hnom_Penh.jpg\#/media/File:Silver_Pagoda,_Phnom_Penh.j pg

[8]. A short history of Cambodia by John Tully

[9]. Copy right- to http://www.swissinfo.ch/eng/cambodiain-transition_reminders-of-a-golden-age/34859034

[10].

Wikipedia

https://en.wikipedia.org/wiki/History_of_Cambodia\#French

_colonial_period_.281863.E2.80.931953.29

[11]. Article

in

https://www.washingtonpost.com/lifestyle/travel/in-phnom-

penh-cambodia-the-french-influence-lives-

on/2014/01/23/8023ea12-7eec-11e3-9556-

4a4bf7bcbd84_story.html

[12]. Post Magazine

http://www.scmp.com/magazines/post-

magazine/article/1421349/vann-molyvann-unsung-herophnom-penh-architecture
[13].
La
Times
Article

http://articles.latimes.com/2010/nov/14/entertainment/la-cacambodian-architect-20101114

[14]. Cambodia Tribunal

http://www.cambodiatribunal.org/history/cambodian-

history/khmer-rouge-history/

[15]. "Chaktomouk Hall" by Anilakeo - Own work. Licensed under CC BY-SA 3.0 via Commons https://commons.wikimedia.org/wiki/File:Chaktomouk_Hall .JPG\#/media/File:Chaktomouk_Hall.JPG

[16]. Open source-http://www.imgneed.com/image/phnompenh-city/general-information-phnom-penh

[17]. "Choeung Ek commemorative stupa filled with skulls". Licensed under Public Domain via Commons https://commons.wikimedia.org/wiki/File:Choeung_Ek_com memorative_stupa_filled_with_skulls.jpg\#/media/File:Choe ung_Ek_commemorative_stupa_filled_with_skulls.jpg

\section{BIOGRAPHIES}

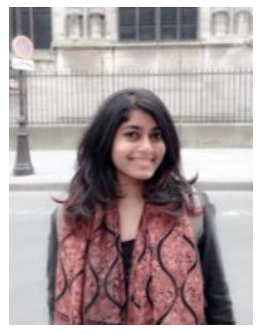

Ankitha Veerepalli, She is a student currently in her $4^{\text {th }}$ year of architecture at GITAM University. She is interested in creating buildings and cities more sustainable and viable for better conditions and longer periods of time through innovative design. 